\title{
LA PROTECCIÓN DE LOS DERECHOS HUMANOS Y LA INEJECUCIÓN DE LAS SENTENCIAS DE AMPARO POR EL INDEBIDO FINANCIAMIENTO DE POLÍTICAS PÚBLICAS EN MÉXICO
}

HUMAN RIGHTS PROTECTION AND THE INEXECUTION OF AMPARO SENTENCES AS A RESULT OF UNDUE FINANCING OF PUBLIC POLICIES IN MEXICO

\section{ROBERTO MARTINEZ REgINO ${ }^{1}$}

RESUMEN: El presente trabajo tiene como objetivo reflexionar el grado de eficacia actual de la protección de los derechos fundamentales por el Estado a través del juicio de amparo, ante la negativa de los órganos públicos de satisfacer a través de bienes y servicios los derechos de las personas, por el indebido financiamiento del ente legislativo. Tema que permite debatir la actualización de instituciones jurídicas necesarias para lograr la concesión de amparo, la creación y modificación de políticas públicas, así como la debida distribución de la riqueza económica en el país para la efectividad de los derechos humanos conforme a estándares del bloque constitucional de derechos humanos.

Palabras Clave: Protección de derechos humanos, inejecución de sentencias de amparo, falta de recursos económicos.

ABSTRACT: The objective of the work is to reflect on the degree of current effectiveness of the protection of fundamental rights by the State through the amparo trial, given the refusal of public bodies to satisfy the rights of individuals through goods and services, for the undue financing of the legislative body. Theme that allows to discuss the updating of legal institutions necessary to achieve the grant of

1 Doctor en Derecho y Globalización por la Facultad de Derecho y Ciencias Sociales de la Universidad Autónoma del Estado de Morelos, actualmente Posdoctorante en Derecho en el Instituto de Investigaciones Jurídicas de la Universidad Nacional Autónoma de México, Correo electrónico: <regino_ct3@hotmail. com>. ORCID: <https://orcid.org/0000-0001-8359-1456>.

Fecha de recepción: 26 de septiembre de 2018; fecha de aprobación: 12 de marzo 2019. 
protection, the creation and modification of public policies, as well as the proper distribution of economic wealth in the country for the effectiveness of human rights in accordance with standards of the constitutional bloc of human rights.

KEYWORDS: Protection of human rights, non-enforcement of amparo judgments, lack of economic resources.

SumArio: I. Introducción; II. El principio de igualdad y el bloque de constitucionalidad de derechos humanos; III. El indebido financiamiento de políticas públicas violatorio de derechos humanos; IV. La tutela judicial, el juicio de amparo y la necesaria distribución de recursos económicos; V. Conclusiones; VI. Fuentes de Información.

\section{INTRODUCCIÓN}

7 n la actualidad el Estado debe cumplir con los objetivos que justifican su existencia; la protección de los derechos fundamentales y el orden social, mientras continúa su evolución ante la influencia de la actual globalización. Así el Derecho no escapa de esta última, generando efectos jurídicos atípicos y también áreas mundializadas "que trascienden las soberanías estatales para convertirse en preocupación, interés o responsabilidad mundial" entre la cuales se encuentran los propios derechos humanos.

La existencia plural de normas jurídicas en la sociedad mundial; por un lado del derecho estatal de los países existentes y por otro el derivado del Derecho internacional y transnacional resultado de las constantes relaciones entre los Estados a través de hard law - tales como tratados internacionales - y soft law - entre ellos resoluciones, informes y recomendaciones de organizaciones internacionales

1 Becerra Ramírez, Manuel et al., "La soberanía en la era de la globalización”, en Becerra Ramírez, Manuel, Müeller Uhlenbrock, Klaus Theodor, Soberanía y juridificación en las relaciones internacionales, México, UNAM-IIJ-Facultad de Estudios Superiores Acatlán, 2010, p.66. 
o conferencias internacionales-; muestra la preocupación en el planeta por el cumplimiento de los derechos de las personas.

Así el Estado mexicano, para el continuo desarrollo de sus funciones y para atender de mejor manera las problemáticas en el contexto global y nacional cuyo intersección lo son los derechos humanos, ha implementado una de las reformas constitucionales más importantes de su historia el 10 de junio del 2011 y al colocar como eje central del sistema jurídico mexicano a los derechos humanos ha roto la inercia en la forma de pensar la juridicidad de diversas instituciones.

Esto implica para nuestro país el deber de proteger, y satisfacer aquellos derechos fundamentales que le corresponden, a través de mecanismos para asegurar su efectividad, operatividad o exigibilidad tales como programas y acciones así como su financiamiento a través del Presupuesto Público conocido en México como Presupuesto de Egresos de la Federación (PEF), un "documento clave y un proceso esencial para manejar la riqueza financiera y de recursos de una sociedad", 2 pues es el proceso "que se sigue para relacionar sistemáticamente la erogación de recursos con la consecución de objetivos previamente establecidos". ${ }^{3}$

Sin embargo, acontece la violación de derechos fundamentales, toda vez que las personas cuya satisfacción de derechos dependen de los servicios en calidad y cobertura, que deben proporcionar los órganos del Estado no pueden ser brindados a falta de dinero o al no ejercicio de este último. La ineficiencia financiera legislativa antes referida se presenta al aprobar la Cámara de Diputados del Congreso de la Unión el PEF en forma anual y de manera discrecional, reduciendo o no asignando recursos económicos a los

2 Blyberg Ann, "The case of the mislaid allocation: economic and social rights and Budget work", Sur.Magazine international journal on human rights, Brasil, São Paulo, V. 6, N. 11, Dec., 2009, p.150.

${ }^{3}$ Chapoy Bonifaz, Dolores Beatriz, Gasto y financiamiento del Estado, México, UNAM-IIJ, 2013, p.1. 
órganos del Estado. Ello aunado a que siendo asignado dinero a los órganos públicos, puede acontecer la existencia de subejercicios y no uso de los recursos económicos para los objetivos destinados.

Atendiendo a lo anterior, las personas acuden al poder judicial o guardián constitucional a exigir el cumplimiento de sus derechos a través del juicio de amparo, donde es necesario que el Juez impulse políticas públicas entre ellas la presupuestaria para el financiamiento de acciones basadas en criterios inherentes al principio de igualdad, estándares constitucionales e internacionales de derechos humanos, para evitar en el futuro el incumplimiento de sentencias de amparo y anticipar futuras tutelas judiciales. De ahí, nuestro interés en la discusión sobre la idoneidad del juicio de amparo y la protección de derechos humanos en la problemática que se plantea.

II. EL PRINCIPIO DE IGUALDAD Y EL BLOQUE DE CONSTITUCIONALIDAD DE LOS DERECHOS HUMANOS

En la actualidad la sociedad mexicana es heterogénea, con una población de 119,938,473 personas aproximadamente 4.6 por ciento en pobreza extrema ${ }^{5}$ y 35.9 en pobreza moderada, con diversas carencias sociales, cuya combinación con otros componentes de vulnerabilidad puede llegar a profundizar esta última, ello dificulta el acceso al goce y ejercicio de derechos fundamentales ante la realidad económica, social y cultural desventajosa, lo que hace imprescindible que el Estado satisfaga los derechos de las personas en forma igualitaria pero también a través de medidas de igualación.

4 Instituto Nacional de Estadística y Geografía, "Población", en: <http:// www.beta.inegi.org.mx/temas/estructura/>, consultado el día 16 de septiembre de 2018.

5 Consejo Nacional de Evaluación de la Política de Desarrollo Social, "Medición de la pobreza", en: <https://www.coneval.org.mx/Medicion/MP/Paginas/ Pobreza_2016.aspx>, consultado el día 16 de septiembre de 2018. 
Lo anterior toma especial relevancia, toda vez que dentro de los derechos fundamentales que le corresponde al Estado proteger y financiar debe atenderse al cumplimiento de parámetros constitucionales tales como el principio de igualdad, características de derechos fundamentales, así como a estándares internacionales de derechos humanos, a través de políticas públicas, esto es, "objetivos públicos compartidos, con el alcance de programas de acción orientados a la consecución de fines sociales valiosos", ${ }^{6}$ y lograr "dar racionalidad al uso de recursos escasos en el cumplimiento de las actividades estatales en cada una de las partes que integran el ciclo de vida". ${ }^{7}$

No obstante lo anterior, se advierte que los derechos de las personas son vulnerados por los entes al no poder satisfacerlos a través de servicios públicos, por acciones u omisiones a causa de la materialización de normas jurídicas imperfectas, políticas públicas deficientes o ausentes, incapacidad institucional para desplegar políticas, así como la indebida asignación de recursos económicos o ejercicio incorrecto de estos últimos; por factores como la discriminación, efecto regresivo, el no ejercicio del uso máximo de recursos económicos y ausencia de la ponderación de derechos para su satisfacción.

En tal sentido, el principio de igualdad se vuelve imprescindible para "el trato igual a las personas, o un trato diferenciado si existen diferencias relevantes, así como la seguridad de una participación equitativa en los recursos o bienes disponibles". ${ }^{8}$ Así, reconocien-

6 Álvarez Ledezma, Mario I, "Derechos Humanos y Políticas Públicas" en Rossi, Andrea, Zavala, Luis Eduardo (coords), Políticas Publicas y Derechos Humanos en México, México, ITESM, 2010, p.121

7 Vazquez, Daniel, De la Place Domitille, "Public Policies from a Human Rights Perspective: A Developing Field", Sur. Magazine international journal on human rights, Brasil, v.8, n.14, jun. 2011, p.40.

8 Vázquez Rodolfo, Derechos Humanos Una lectura liberal igualitaria, México, UNAM-IIJ-ITAM-CEAD, 2017, p.5. 
do la igualdad y pese a las diversas diferencias y respuestas a estas últimas, siempre el marco de referencia será que los seres humanos somos moralmente iguales.

No obstante lo anterior, y pese a la inserción en diversos ordenamientos normativos desde la Constitución e infra constitucionales del principio de igualdad así como de la cláusula de prohibición de discriminación negativa ${ }^{9}$ entendida como "una relación social en la que un grupo con capacidad de ejercer alguna o varias formas de dominio (económico, político, cultural) minusvalora o repele a otro grupo, colocándolo en una situación de desigualdad u opresión", ${ }^{10}$ - donde se toma como base alguno de los rasgos del grupo excluido para crear estereotipos de inferioridad, inmoralidad o peligrosidad - su cumplimiento en la práctica presenta una gran asimetría, distanciando la protección ${ }^{11}$ de la dignidad de las personas así como la construcción de una sociedad verdaderamente democrática.

Lo anterior es así, a falta de atención ${ }^{12}$ de dos de sus rasgos principales: la subordinación grupal y el carácter estructural, pues la existente construcción de una relación de subordinación intergrupal vinculada a algún rasgo característico que la singulariza a este último, se reproduce sistémica y sistemáticamente, de ahí la

9 Artículos 1 y 4 primer párrafo, 12, 13, de la Constitución Política de los Estados Unidos Mexicanos, así como en los artículos 1, 2 y 7 de la Declaración Universal de Derechos Humanos, artículo II de la Declaración Americana de los Derechos y Deberes del Hombre, artículos 2.1, 3 y 26 del Pacto Internacional de Derechos Civiles y Políticos, artículos 2 y 3 del Pacto Internacional de Derechos Económicos, Sociales y Culturales, y artículos 1 y 24 de la Convención Americana sobre Derechos Humanos "Pacto de San José".

10 Gutiérrez Rivas, Rodrigo, Salazar Ugarte, Pedro, Igualdad, no discriminación y derechos sociales. Una vinculación virtuosa, México, CONAPRED, 2011 , p.43.

11 Cfr. Ibidem, p. 45.

12 Cfr. Gutiérrez Rivas, Rodrigo, "La categoría de discriminación y su relación con el paradigma de los derechos humanos: un apunte crítico" en Anglés Hernández, Marisol, Burgos Matamoros Mylai, Capdevielle Pauline, Sin Derechos, exclusión y discriminación en el México actual, Colección Líneas de investigación institucionales, México, UNAM, 2014, pp.11-12. 
necesidad de dirigir el enfoque dominante al de "una desigualdad de poder entre los grupos y no solo como una diferencia de trato entre las personas"13 a través de acciones positivas para lograr "la redistribución de bienes y posiciones sociales con un correspondiente sacrificio de los intereses de los grupos que se encuentran en situación de poder". ${ }^{14}$

Pues pese a la existencia de diversas medidas de igualdad formal - conforme a los cuales no puede hacerse distinción en perjuicio de persona alguna al estar prohibido por una ley general, abstracta e impersonal - y su transición a la igualdad material — donde deben reconocerse diferencias de quienes integran la sociedad sin que ello implique desventajas - su naturaleza nos permite apreciar la necesaria complementación de ambas así como la implementación de un criterio de razonabilidad como una herramienta para el control de disposiciones normativas y de políticas públicas.

Ello es así, pues el carácter sistémico de la discriminación directa, esto es, "el tratamiento diferenciado basado en alguno de los rasgos prohibidos que vulnere derechos fundamentales" 15 o indirecta, el cual "se produce cuando el derecho da un tratamiento formalmente neutro entre grupos o personas que en los hechos son diferentes, por lo que el grupo en posición de mayor debilidad se ve afectado", ${ }^{16}$ traen consigo graves afectaciones a las estructuras sociales, económicas y políticas, impidiéndoles a las personas el cumplimiento de derechos fundamentales.

En este contexto, dentro de las obligaciones del Estado de promover, respetar, proteger y garantizar los derechos fundamentales, el último de ellos llama nuestra atención al consistir en "el deber de los Estados Partes de organizar todo el aparato gubernamental y,

\footnotetext{
13 Ibidem, p. 12.

14 Ibidem, p. 13.

15 Gutiérrez Rivas, Rodrigo, Salazar Ugarte, Pedro, op.cit., p.50.

16 Idem, p.50.
} 
en general, todas las estructuras a través de las cuales se manifiesta el ejercicio del poder público, de manera tal que sean capaces de asegurar jurídicamente el libre y pleno ejercicio de los derechos humanos". ${ }^{17}$

Lo anterior es una situación que si bien se ha innovado en forma importante con la actualización al marco normativo mexicano, no es suficiente, al necesitarse también acciones a través de políticas públicas debidamente financiadas, que materialicen el contenido de los mandatos constitucionales y convencionales, protegiendo así los derechos humanos, tal como ha indicado la Corte Interamericana de Derechos Humanos: "no se agota con la existencia de un orden normativo dirigido a hacer posible el cumplimiento de esta obligación, sino que comparta la necesidad de una conducta gubernamental que asegure la existencia, en la realidad, de una eficaz garantía del libre y pleno ejercicio de los derechos humanos".$^{18}$

Como puede apreciarse, la concepción de la igualdad debe reconocer las diferencias de la sociedad mexicana, y con ello identificar que no basta con insertar derechos humanos en las normas jurídicas de orden constitucional, infra constitucional o de fuente internacional, sino que deben diseñarse políticas públicas con la suficiente asignación de recursos económicos a fin de que estas brinden respuestas a las necesidades de las personas y satisfagan los derechos humanos correspondientes.

En este contexto, frente a la existencia del valor de la igualdad en el sistema normativo mexicano, se aprecia también el bloque de constitucionalidad de derechos humanos, el cual es denominado como "la unidad inescindible y permanente de derechos fundamentales de fuente constitucional e internacional reconocidos por el ordenamiento jurídico mexicano, caracterizados por estar elevados al máximo rango normativo y, como consecuencia, compartir el

\footnotetext{
17 Corte IDH, Caso Velásquez Rodríguez vs. Honduras (1998), párr. 166.

18 Ibidem, párr. 167.
} 
mismo valor constitucional, sin que ninguno de ellos tenga una preeminencia formal sobre los otros", ${ }^{19}$ es decir, una técnica a través de la cual se interpreta, aplica o desaplica las normas y principios no contenidos en la constitución, pero insertos a través del reenvío de esta última a otros cuerpos normativos, tales como de fuente internacional.

En mérito de lo anterior, al insertarse en la Constitución Política de los Estados Unidos Mexicanos (CPEUM) las características de los derechos fundamentales; ${ }^{20}$ universalidad, interdependencia, indivisibilidad y progresividad, así como diversos parámetros o estándares internacionales tales como: ${ }^{21}$ uso máximo de recursos, progresividad, medidas adecuadas, recursos efectivos, tomar en cuenta el desarrollo del país, la no discriminación, niveles mínimos de satisfacción de los derechos y protección de miembros vulnerables de la sociedad en tiempos graves de recursos, derivado del

19 Astudillo, Cesar, "El bloque y el parámetro de constitucionalidad en la interpretación de la Suprema Corte de Justicia de la Nación”, en Carbonell, Miguel, Fix-Fierro, Héctor, González Pérez, Luis Raúl, Valadés Diego (Coordinadores), Estado constitucional, derechos humanos, justicia y vida universitaria. Estudios en homenaje a Forge Carpizo. Estado Constitucional, México, UNAM-IIJ, 2015, Tomo IV, Volumen 1, p. 121 .

20 Artículo 1 de la Constitución Política de los Estados Unidos Mexicanos.

21 Atendiendo a ordenamientos internacionales como la Declaración Universal de los Derechos Humanos, Pacto Internacional de Derechos Civiles y Políticos, Pacto Internacional de Derechos Económicos, Sociales y Culturales, Observación General Número 3 "La índole de las obligaciones de los Estados Partes (párrafo 1 del artículo 2 del Pacto)" aprobada por el Comité de Derechos, Económicos, Sociales y Culturales, Observación General Numero 9 "La aplicación interna del Pacto" aprobada por el Comité de Derechos Económicos, Sociales y Culturales, Convención Americana de Derechos Humanos, Protocolo Adicional a la Convención Americana sobre Derechos Humanos en materia de derechos económicos, sociales y culturales "Protocolo de San Salvador", documento de avance sobre las normas para la confección de los informes periódicos previstos en el artículo 19 del Protocolo de San Salvador, Declaración E/C. 12/2007/1 del Comité de Derechos Económicos, Sociales y Culturales del 21 de septiembre de 2007, entre otros. 
hard law firmados y ratificados por México, su cumplimiento debe materializarse a través de acciones del propio Estado.

Como puede apreciarse, el actual bloque de constitucionalidad en materia de derechos humanos permite apreciar que estos últimos deban ser satisfechos por el Estado a través de políticas, debida asignación y ejercicio de recursos económicos que desplieguen bienes y servicios, impregnadas de igualdad objetiva y razonable así como de aquellos estándares constitucionales e internacionales de derechos humanos.

III. EL INDEBIDO FINANCIAMIENTO DE POLÍtICAS PÚBLICAS VIOLATORIO DE DERECHOS HUMANOS

La realidad permite apreciar que los derechos fundamentales pueden ser violados o afectados por políticas públicas - aun cuando estas últimas "tienen como principal objetivo dar racionalidad al uso de recursos escasos en el cumplimiento de las actividades estatales en cada una de las partes que integran el ciclo de vida"22 como es por el Presupuesto Público — que en países como México solo se refiere al gasto público - debido a la raíz de "una distribución desigual de la riqueza y recursos de la sociedad". ${ }^{23}$

Atendiendo a lo anterior, el gasto social en México es bajo a pesar de los continuos aumentos en las décadas pasadas, hoy "representa solo un tercio del promedio de la OCDE. De hecho, el gasto social de México es menor que el de Chile, Colombia, Brasil o Costa Rica", ${ }^{24}$ ello aunado ${ }^{25}$ a problemas estructurales tales como la ineficacia del PEF y la corrupción que impiden el incremento del gasto e inversión social.

22 Vazquez, Daniel, De la Place Domitille, op.cit., p.40.

23 Blyberg Ann, op.cit., p. 150.

24 Organización para la Cooperación y el Desarrollo Económicos, Getting it Right Prioridades Estratégicas para México, Francia, Éditions OCDE, 2018, p.79.

25 Cfr. Ibidem, p.80. 
Por consiguiente, no basta con insertar derechos humanos en ordenamientos jurídicos, pues no trae por sí mismo su cumplimiento, sino que se requiere de políticas entre ellas el PEF, con la cual se asignen debidamente recursos económicos a los órganos del Estado atendiendo a los parámetros constitucionales e internacionales de derechos humanos para que se brinden servicios con los cuales se satisfagan derechos a favor de las personas.

Asimismo, acontece que las personas al tratar de satisfacer ciertas necesidades a través de servicios públicos, acuden a las instituciones de diversas esferas de competencias y al recibir la negativa a aquellos en calidad o cobertura, ante la falta de dinero para finanzar insumos o personal, se violan derechos fundamentales tales como acceso a la salud, a la educación, a la seguridad pública, por mencionar algunos.

En este contexto, a pesar de la existencia de dichos mandatos normativos, en la realidad acontece violación a derechos humanos, debido a que las políticas públicas con las cuales deben satisfacerse aquellos, no son desplegadas por los órganos públicos ante: a) la no asignación de recursos económicos o la reducción injustificada de la partida presupuestal por el ente legislativo de manera anual, y b) habiéndosele asignado, deciden no ejercer dichos montos al fin determinado. Así, ante las causas referidas de las que deriva el inadecuado reparto de la riqueza del país, estas se presentan en las siguientes modalidades:

1. Por ACCIÓN U OMISIÓN EN LA APROBACIÓN DEL PRESUPUESTO PÚBLICO

\section{A) Por acción legislativa}

Se presenta al aprobar el presupuesto el ente legislativo - en México solo por la Cámara de Diputados - en forma anual — salvo ciertas excepciones - a través de la pluralidad de diputados al decidir 
con toda intención por medio de actuaciones; no asignar o reducir partidas presupuestarias hacia rubros destinados a los órganos del Estado que prestan bienes y servicios a la población mexicana.

\section{B) Por omisión Legislativa}

Si bien es cierto puede acontecer la inconstitucionalidad por omisión en sentido extenso, donde la omisión normativa se puede presentar por "la falta o ausencia de creación de normas jurídicas, en la que puede incurrir no solo el legislador sino incluso otros órganos del Estado"26, en forma concreta y por lo que el tema se refiere puede suceder que al aprobar la Cámara de Diputados el gasto público, sean omisos en forma total o parcial en la asignación de recursos económicos, contrariando a la CPEUM al no poder satisfacer el Estado la protección de derechos fundamentales y diversas funciones públicas con dicha política ante una distribución inequitativa del dinero a los entes del Estado, aconteciendo la inconstitucionalidad de la omisión legislativa, el incumplimiento del legislador de crear una norma jurídica concreta, por mandato constitucional en un tiempo determinado, en otras palabras, “...la falta de desarrollo por parte del Poder Legislativo, durante un tiempo excesivamente largo, de aquellas normas constitucionales de obligatorio y concreto desarrollo, de forma tal que se impide su eficaz aplicación". ${ }^{27}$

En tal sentido, si se atiende a este fenómeno bajo la forma absoluta - al no crear totalmente las disposiciones indicadas-y relativa - creándolas se hace en forma parcial-, así como a las competencias del ente legislativo: obligatorias — "donde el órgano legislativo no tiene posibilidad de decidir si crea o no una norma

26 Báez Silva, Carlos, La inconstitucionalidad por omisión legislativa en México, México, Porrúa, 2009, p.33.

27 Fernández Rodríguez, José Julio, “Inconstitucionalidad por omisión”, en Carbonell, Miguel, (Coordinador), En busca de las normas ausentes, México, UNAMIIJ, 2007, p.13. 
general determinada, sino que existe un mandato o una obligación a su cargo de expedir determinada ley"28_ y potestativas _ "... el órgano legislativo decide, libremente, si crea o no determinada norma jurídica y en qué momento lo hará"29_, surge una interesante tipología definida por la Suprema Corte de Justicia de la Nación $(\mathrm{SGJN}):{ }^{30}$

a) Absolutas en competencias de ejercicio obligatorio, cuando el órgano legislativo tiene la obligación o mandato de expedir una determinada ley y no lo ha hecho; b) Relativas en competencias de ejercicio obligatorio, cuando el órgano legislativo emite una ley teniendo una obligación o un mandato para hacerlo, pero lo realiza de manera incompleta o deficiente; c) Absolutas en competencias de ejercicio potestativo, en las que el órgano legislativo decide no actuar debido a que no hay ningún mandato u obligación que así se lo imponga; y, d) Relativas en competencias de ejercicio potestativo, en las que el órgano legislativo decide hacer uso de su competencia potestativa para legislar, pero al emitir la ley lo hace de manera incompleta o deficiente.

Variantes a las cuales la inconstitucionalidad por omisión legislativa puede presentarse cuyos efectos trascienden y afectan los derechos de las personas.

\section{Subejercicios en la ejecución del gasto público}

\section{A) Por acción administrativa}

No puede descartarse de igual forma, que una vez proporcionados recursos económicos por el ente legislativo a los demás órganos existentes en el país, estos últimos por actos determinen no ejercer

28 Báez Silva, Carlos, op.cit., p.83.

29 Idem.

30 Cfr. Tesis: P./J. 11/2006, Semanario Judicial de la Federación y su Gaceta, Novena Época, Tomo XXIII, febrero de 2006, p. 1527. 
correctamente el dinero, aconteciendo subejercicios o el incumplimiento de objetivos y metas del gasto público, es decir, "las disponibilidades presupuestarias que resultan, con base en el calendario de presupuesto, sin cumplir las metas contenidas en los programas o sin contar con el compromiso formal de su ejecución" ${ }^{31}$ por una indebida estrategia financiera o por desvíos de dinero, imposibilitando la aplicación de tales recursos económicos a los bienes y servicios con los que deben satisfacerse derechos fundamentales, por los entes públicos en forma directa o indirecta.

\section{B) POR OMISIÓN ADMINISTRATIVA}

Asimismo, es susceptible de acontecer la no realización de actos para destinar los recursos económicos al fin específico de la partida presupuestal, transcurriendo el tiempo para que dicho dinero pueda redirigirse a otro rubro o simplemente no ejercerse, lo cual puede ser efecto de la ignorancia o negligencia de las personas responsables de la administración de tal recurso.

De tal manera, atendiendo la actividad formal del titular de la administración pública federal, así como a las funciones materialmente administrativas de los demás poderes y órganos constitucionalmente autónomos, es susceptible de acontecer la inconstitucionalidad por omisión administrativa, conforme al cual pese a que existen deberes directos por mandato constitucional no son cumplidas tales obligaciones trascendiendo en la prestación de servicios públicos y el detrimento de derechos humanos.

Como puede apreciarse, es notorio el uso de la facultad discrecional para distribuir los recursos económicos a los órganos del Estado, contrastando con los compromisos constitucionales y del Derecho Internacional de Derechos Humanos, cuyo resultado se presenta en

31 Artículo 2, fracción LII de la Ley Federal de Presupuesto y Responsabilidad Hacendaria. 
la indebida asignación presupuestaria, no racionalización del dinero y el no uso del dinero para el fin señalado.

IV. LA TUTELA JUDICIAL, EL JUICIO DE AMPARO Y LA NECESARIA DISTRIBUCIÓN DE RECURSOS ECONÓMICOS

Como se ha referido con antelación, al incumplir mediante acción u omisión el Estado a través de sus diversos entes, la satisfacción de derechos fundamentales insertos en el actual bloque de constitucionalidad a través de bienes y servicios, permite al justiciable acudir al guardián constitucional para exigir su cumplimiento a través de las decisiones de los jueces.

En la relación indisoluble entre el presupuesto y los derechos humanos, la expansión de estos últimos trae consigo efectos en el derecho presupuestario, pues uno de los objetivos de este último es hacer que los derechos fundamentales sean efectivos. Los principios del bloque antes referido, limitan la discrecionalidad del legislador en materia presupuestaria y posibilita el control judicial de las políticas públicas, como resultado de la ineficacia en las decisiones que por tradición han correspondido a otros entes públicos.

Frente a la positivización de derechos fundamentales debe existir asignación económica a las políticas públicas que habrá de efectivizar a los primeros, por ello capta nuestra atención el PEF porque a través de ella el Estado financia bienes y servicios para las personas, sin embargo, debido a los principales rezagos en la actualización de la institución presupuestaria - la separación entre la parte de ingresos y la de gastos, el hermetismo procedimental que impide la participación ciudadana en su diseño y aprobación, la negativa de ser considerada como ley - se impide el objetivo antes referido.

Ante la violación de los derechos fundamentales por esta problemática y a la existencia de instituciones y procedimientos jurisdiccionales así como no jurisdiccionales para la defensa de la CPEUM, se atiende a los primeros como "mecanismos e instrumentos que es- 
tán enfocados hacia el control de la constitucionalidad y la defensa de la Constitución", ${ }^{32}$ así pese a la existencia del control de convencionalidad interna - donde los jueces locales y algunos federales que no conocen por vía directa de control constitucional, pueden inaplicar la norma si es contraria a la Constitución o a tratados internacionales en materia de derechos humanos - el enfoque se centra en el control de constitucionalidad, ${ }^{33}$ y ante los diversos medios imperantes en el país, ${ }^{34}$ se hace referencia al juicio de amparo, medio de control constitucional correctivo por excelencia para proteger los derechos fundamentales de los justiciables y conforme al cual es posible declarar inconstitucional un acto, omisión o norma por ser contrario a la CPEUM.

Así el juicio de amparo, al ser un medio con el cual se pretende garantizar el principio de tutela judicial efectiva reconocido en diversas disposiciones ${ }^{35}$ y por medio de sus diversas modalidades: “a) La libertad de acceso a la justicia, eliminando los obstáculos pro-

32 Uribe Arzate, Enrique, "Mecanismos e instrumentos para la justicia constitucional", en Corzo Sosa, Edgar, I Congreso internacional sobre justicia constitucional, México, UNAM, 2009, p.474.

$33 \mathrm{Al}$ respecto puede consultarse la Tesis: 1a./J. 18/2012 (10a.), Semanario Judicial de la Federación y su Gaceta, Décima Época, Libro XV, Diciembre de 2012, Tomo 1, p.420, asimismo, Tesis: P. LXVII/2011(9a.), Semanario Judicial de la Federación y su Gaceta, Décima Época, Libro III, Diciembre de 2011 , Tomo 1, p.535.

34 1.- El juicio de amparo, 2.- La declaratoria, por parte del Senado, de que ha llegado el caso de nombrar un gobernador provisional, 3.- La competencia del Senado para resolver, en los términos de la fracción VI del artículo 76 constitucional, las cuestiones políticas que surjan entre los poderes de una entidad federativa, 4.- La facultad de investigación ahora asignada a la Comisión Nacional de Derechos Humanos, 5.- El juicio de responsabilidad política, 6.- La controversia constitucional, 7.- La acción de inconstitucionalidad, 8.- Y el Ombudsman mexicano. Carpizo, Jorge, Carbonell, Miguel, Derecho Constitucional, México, Porrúa, 2010 , p. 13.

35 Artículo 17 de la CPEUM, ordinal 25 de la Convención Americana sobre Derechos Humanos, artículo 2 párrafo tercero del Pacto Internacional de Derechos Civiles y Políticos, y los párrafos A1-A3, B4 y C9 de la Observación General 
cesales que pudieran impedirlo. b) La obtención de una sentencia de fondo, motivada y fundamentada, en un tiempo razonable. c) La ejecutoriedad o cumplimiento del fallo", ${ }^{36}$ se podrá identificar que si bien esta garantía cumple con la primera de las etapas referidas, presenta problemas en las últimas dos respecto al tema que se trata como a continuación se advierte.

El adecuado planteamiento que pueden formular los justiciables en presentar la demanda de amparo, a través del litigio estratégico, "recurso y herramienta fundamental para un programa de expansión de derechos y de incidencia en políticas de derechos humanos" 37 con el fin de hacer exigibles sus derechos fundamentales, determina en parte el resultado de la sentencia y la ejecución de esta última. De tal manera, el inicio del proceso de amparo atiende a dos diferentes formas:

\section{De manera directa respecto al PeF}

La cual consiste en impugnar en forma frontal el gasto público, con el fin de lograr la redistribución en forma equitativa de la riqueza del país a los entes públicos; entre ellos a la autoridad que no cuenta con recursos asignados, ante la indebida aprobación mediante el uso de la facultad discrecional por el ente legislativo, sin sujetarse a los parámetros de derechos humanos del bloque de constitucionali-

N 9 "La aplicación interna del Pacto" aprobada por el Comité de Derechos Económicos, Sociales y Culturales.

36 Pardo Rebolledo, Jorge Mario, "El papel de las cortes constitucionales en la justiciabilidad de los derechos económicos, sociales y culturales", en Cervantes Alcayde, Magdalena, et. al., (coordinadores), ¿Hay justicia para los derechos económicos, sociales y culturales? Debate abierto a propósito de la reforma constitucional en materia de derechos humanos, México, SCJN-UNAM-IIJ, 2014, p.132.

37 Centro de Estudios Legales y Sociales (CELS), Litigio estratégico y derechos humanos. La lucha por el derecho, Argentina, Centro de Estudios Legales y Sociales (CELS)- XXI Siglo veintiuno Editores, 2008, p.19. 
dad. De tal manera, dicha discusión en sede judicial puede atender a dos modalidades:

\section{A) Por acción legislativa}

Ante el rezago jurídico de la institución presupuestaria en diferentes temas, hoy su naturaleza jurídica, toma vital trascendencia, debido que la propia SCJN ha indicado que el PEF es un acto materialmente administrativo y no un acto jurídico formal, ${ }^{38}$ esto es, el gasto público es un acto de aplicación de la ley de presupuesto sin que otorgue competencias ni mucho menos derechos y obligaciones. ${ }^{39}$

La realidad, en cambio permite entender que el gasto público es una norma jurídica; general, abstracta e impersonal debido a que es el resultado del proceso legislativo para controlar la gestión y aplicación de los recursos públicos y en consecuencia debe reconocérsele tal naturaleza. Esta situación, parece no encontrar problema alguno ante la modificación del PEF por gastos no previstos cuya autorización corresponde al H. Congreso de la Unión. ${ }^{40}$

Ello resulta de vital importancia, pues mientras no sea considerada como ley o norma general, existe imposibilidad de ser impugnada no solo por los mismos órganos del Estado o por personas, por ser violatoria de derechos, al reducir o no asignar, vía acción u omisión legislativa recursos económicos a las entidades públicas a fin de que brinden bienes y servicios a la sociedad y con ello efectivizar sus derechos.

$38 \mathrm{Al}$ respecto es sostenido tal postura en la Tesis: P. XIV/2007, Semanario Judicial de la Federación y su Gaceta, Novena Época, Tomo XXV, Mayo de 2007, p. 1533 .

$39 \mathrm{Al}$ respecto puede consultarse la Tesis: P./J. 24/99, Semanario Judicial de la Federación y su Gaceta, Novena Época, Tomo IX, Abril de 1999, p.251.

40 Cfr. Artículo 126 de la Constitución Política de los Estados Unidos Mexicanos. 
Así aun cuando pudiera ser impugnado como un acto el PEF, pese a las últimas actualizaciones al juicio de amparo y ante la jurisprudencia de la $\mathrm{SCJN}$, los efectos relativos de la sentencia de amparo impediría el alcance de la modificación del gasto público como lo indica el artículo 73 de la Ley de Amparo.

No obstante lo anterior, si bien en forma inicial el interés jurídico justificó la relatividad de la sentencia en el juicio de amparo, el tiempo actual y las necesidades sociales, permiten entender que del propio interés jurídico e interés legítimo - partiendo de cierta casuística y a ciertos derechos - pueden expandirse los beneficios que traen consigo los efectos de la sentencia hacia personas que no fueron parte en el proceso bajo la actual fórmula Otero, empero, hoy es una necesidad la implementación de efectos generales a la sentencia de amparo ante problemáticas como la que se atiende, puesto que el impulso de políticas públicas requieren no solo la gestión de recursos económicos por parte de autoridades responsables sino la debida asignación presupuestaria por el ente legislativo.

B) Por omisión Legislativa

La utilización de esta garantía ante el problema planteado, se encuentra limitada por los efectos relativos de la sentencia concesoria de amparo que pudiera resultar. Ello se aprecia de la interpretación que ha hecho al respecto la SCJN en forma constante y uniforme ${ }^{41}$ así como al imperar la actual jurisprudencia sobre la omisión le-

41 Tesis: P. CLXVIII/97, Semanario Judicial de la Federación y su Gaceta, Novena Época, Tomo VI, Diciembre de 1997, p. 180, P. LXXX/99, Semanario Judicial de la Federación y su Gaceta, Novena Época, Tomo X, Noviembre de 1999, p. 40, P./J. 134/2008, Semanario Judicial de la Federación y su Gaceta, Novena Época, Tomo XXVIII, Octubre de 2008, p.43, Tesis: 2a. XII/2009, Semanario Judicial de la Federación y su Gaceta, Novena Época, Tomo XXIX, Marzo de 2009, p. 475, respecto a pleno y salas. En relación a Tribunales Colegiados de Circuito con la tesis: Tesis: IV.2o.A.56 A, Semanario Judicial de la Federación, Novena Época, Tomo XIX, Enero de 2004, p. 1549, y la Tesis: II.2o.P.74 P, Se- 
gislativa genérica que indica: "tal violación constituye una omisión legislativa que no puede repararse a través del amparo, puesto que a virtud de sus efectos no puede obligarse al legislador ordinario a colmar la falta de previsión en esta materia, dado que el efecto relativo de las sentencias de amparo lo impide" ,42 misma que resulta similar en materia presupuestaria al indicar la Corte que: ${ }^{43}$ el juicio de amparo es improcedente contra omisiones legislativas a fin de que se destine a través del PEF una partida para el Fideicomiso que administrará el Fondo de Apoyo Social para Ex trabajadores Migratorios Mexicanos, toda vez que ello implicaría una redistribución de recursos mediante un acto legislativo de carácter general, abstracto y permanente, lo que es imposible con el amparo.

Como puede apreciarse a través de la impugnación directa del PEF vía amparo, no es posible la emisión de sentencia favorable en la protección de derechos humanos por el efecto relativo de dicha garantía. Debido a ello, y ante la problemática referida los justiciables se encuentran intentando una segunda alternativa que a continuación se trata.

\section{EN FORMA INDIRECTA}

Impugnando la afectación de los derechos fundamentales por el acto u omisión de la autoridad que genera la negativa de proporcionar el servicio o brindándolo lo hace en forma deficiente, sin la cobertura esperada al carecer de recursos económicos o al no desear ejercerlos para el fin destinado.

manario Judicial de la Federación, Novena Época, Tomo XVIII, Julio de 2003, p. 1024.

42 Tesis: P./J. 134/2008, Semanario Judicial de la Federación y su Gaceta, Novena Época, Tomo XXVIII, Octubre de 2008, p.43.

43 Cfr. Tesis: IX.1o.5 A (10a.), Semanario Judicial de la Federación y su Gaceta, Décima Época, Libro XXIV, Septiembre de 2013, Tomo 3, p.2620. 
Esta exigibilidad de derechos humanos en sede judicial, en el que se ha buscado por parte del justiciable la emisión de sentencia concesoria de amparo debiendo las autoridades responsables proteger los derechos controvertidos, pese a que no ha traído consigo el mandamiento de que el ente legislativo pueda redistribuir el gasto público atendiendo a los efectos relativos del juicio de amparo, ha gestado el inicio de precedentes por la SCJN en materia presupuestal que pretenden actualizar su juridicidad y mejor distribución de la riqueza para que en su relación con los derechos humanos estos sean efectivos: ${ }^{44}$

a) La modificabilidad presupuestaria, la cual permite comprender que el PEF puede ajustarse no solo ante una realidad donde acontece bonanza en la riqueza que percibe el Estado o en su caso crisis económica sino inclusive por orden judicial ante una violación de derechos al aprobar el PEF y no asignar o reducir en forma injustificada recursos económicos para bienes y servicios que ya proporciona o debería proporcionar el Estado. ${ }^{45}$

b) El deber de los órganos del Estado de adoptar todo tipo de mecanismos para eficientar los recursos de la partida presupuestal previamente autorizada con independencia de la solicitud formulada para que el ente legislativo amplíe

$44 \mathrm{Al}$ respecto puede consultarse las Tesis: P. XX/2002, Semanario Judicial de la Federación y su Gaceta, Novena Época, Tomo XV, Abril de 2002, p.12, Tesis: P./J. 5/2011, Semanario Judicial de la Federación y su Gaceta, Novena Época, Tomo XXXIII, Marzo de 2011, p.10, Tesis: II.1o.T.6 L (10a.), Semanario Judicial de la Federación y su Gaceta, Décima Época, Libro XVII, Febrero de 2013, Tomo 2, p.1301, y respecto al último de los criterios las Tesis: I.3o.(I Región) 19 A (10a.), Gaceta del Semanario Judicial de la Federación, Décima Época, Libro 1, Diciembre de 2013, Tomo II, p.1207, y la Tesis: I.3o.(I Región) 20 A (10a.), Gaceta del Semanario Judicial de la Federación, Décima Época, Libro 1, Diciembre de 2013 , Tomo II, p. 1208.

45 Tesis: P. XX/2002, Semanario Judicial de la Federación y su Gaceta, Novena Época, Tomo XV, Abril de 2002, p. 12. 
la partida presupuestal y pueda cumplimentar la sentencia de amparo. ${ }^{46}$

c) La obligación de las autoridades responsables de elaborar el PEF y la del juez natural de coadyuvar para que le sea asignado al Tribunal respectivo una partida presupuestal razonable que le garantice al quejoso la atención y administración de justicia pronta y expedita. ${ }^{47}$

d) El interés de impulsar el cambio de criterio sostenido por la SGJN respecto a la naturaleza del PEF, por tribunales que comienzan a advertir lo que ya es evidente, que el PEF es una norma jurídica en sentido formal como material, debido a que la parte respectiva de ingresos y la de gastos forman parte de un acto legislativo que no es más que una ley, así el PEF es una norma jurídica en sentido formal al ser aprobado por la Cámara de Diputados conforme al artículo 74, fracción IV Constitucional, pero también materialmente al regular la forma de gastar el dinero del Estado, y en consecuencia crea, modifica o extingue situaciones jurídicas de la administración como de particulares - acreedores y deudores - a quienes se encuentra dirigida. ${ }^{48}$

Como puede apreciarse, una vez incoada demanda de amparo en busca de la justicia de la unión, en el supuesto de concederse esta última, se vuelve necesaria la postura que asumirá el guardián cons-

46 Tesis: P./J. 5/2011, Semanario Judicial de la Federación y su Gaceta, Novena Época, tomo XXXIII, Marzo de 2011, p. 10.

47 Tesis: II.1o.T.6 L (10a.), Semanario Judicial de la Federación y su Gaceta, Décima Época, Libro XVII, Febrero de 2013, Tomo 2, p. 1301.

$48 \mathrm{Al}$ respecto puede consultarse: Tesis: I.3o.(I Región) 19 A (10a.), Gaceta del Semanario Judicial de la Federación, Décima Época, Libro 1, Diciembre de 2013, Tomo II, p.1207. Asimismo, la Tesis: I.3o. (I Región) 20 A (10a.), Gaceta del Semanario Judicial de la Federación, Décima Época, Libro 1, Diciembre de 2013, Tomo II, p. 1208. 
titucional respecto a la judicialización de la política y la manera en la que a través de sus sentencias impulsaran las políticas públicas y su financiamiento. En un escenario donde las sentencias de amparo que se emiten se caracterizan por ser declarativas directas, mediante las cuales los jueces en forma monológica ordenan a las autoridades responsables que es lo que deben hacer, dar o no hacer a través de políticas y las actividades a implementar en la ejecución de la sentencia respecto a la protección a los derechos protegidos, empero, el derecho comparado nos ofrece un acervo jurídico al tema:

1. Dentro de las propias decisiones unilaterales de los juzgadores posibles de adoptar, se encuentran las sentencias atípicas de tipo intermedio aditivas esto es, "sin afectar por lo regular al texto de la disposición impugnada entienden que a la disposición impugnada le falta algo para ser completamente conforme con la Constitución, produciendo un efecto de ampliación o extensión en el contenido normativo de la misma, permitiendo de este modo su aplicación a supuestos no contemplados expresamente en la disposición"49 — utilizadas en la Corte Constitucional Italiana, el Tribunal Constitucional de España, Portugal, Austria y Colombia - y sustitutivas "que declaran la inconstitucionalidad de una parte textual del precepto impugnado (este es el supuesto más común), al tiempo que disponen que la parte declarada inconstitucional se sustituya por otra indicada por el propio Tribunal Constitucional"50 usadas en la Corte Constitucional Italiana y por el Tribunal Constitucional de España, los cuales pueden ser útiles al agregar o sustituir contenido de igualación o estándares del bloque

49 Figueroa Mejía, Giovanni A., Las sentencias constitucionales atípicas en el derecho comparado y en la acción de inconstitucionalidad mexicana, México, Porrúa, 2011, p.164. 50 Ibidem, p. 184. 
de constitucionalidad en las propias normas jurídicas y políticas públicas a aplicarse.

2. Dentro de las soluciones bilaterales donde los jueces y el ente legislativo u otras entidades públicas colaboran para resolver el problema controvertido se encuentran ${ }^{51}$ fallos de inconstitucionalidad sin nulidad, sentencias de apelación - con la que exhorta, apela o comunica "al órgano legislativo para que sustituya la normatividad declarada inconstitucional, conforme los principios y lineamientos establecidos en la propia sentencia, pudiendo señalar un plazo prudente para ello"52 - las que declaran que la ley aun no es inconstitucional pero puede serlo en el futuro, el retraso de los efectos de la sentencia para dar tiempo a la intervención del legislador, los cuales pueden ser aplicables para eficientar la funcionalidad de las normas jurídicas, la prestación de servicios y su financiamiento más equitativo.

3. Sentencias dialógicas entre el poder judicial y otros poderes o autoridades de distintas competencias, donde los jueces atienden casos individuales, colectivos y estructura$\operatorname{les}^{53}$ basadas por la elección que tomen los jueces respecto

51 Para mayor información puede consultarse la obra de Díaz Rivorio, Francisco Javier, Interpretación de la constitución y justicia constitucional, México, PorrúaIMDPG, 2009, p. 106.

52 Fix-Zamudio, Héctor, Ferrer Mac Gregor, Eduardo, Las sentencias de los tribunales constitucionales, Lima, Centro de Estudios Constitucionales-Tribunal Constitucional-Adrus S.R.L., 2009, p. 69.

53 "Procesos judiciales que se caracteriza por a) afectar a un gran número de personas que denuncian la violación de sus derechos, por si mismas o mediante organizaciones que presentan demandas judiciales en su nombre; b) involucrar a varios organismos y departamentos del Estado, que se consideren responsables de las persistentes fallas de política pública que contribuyen a la violación de esos derechos, y c) y llevar aparejadas medidas estructurales..." Rodríguez Garavito, Cesar, "El activismo dialógico y el impacto de los fallos sobre derechos sociales", en Roberto Gargarella (Compilador), Por una justicia dialógica. El Poder Fudicial como 
a tres elementos importantes: "el contenido sustantivo, las medidas judiciales y los mecanismos de seguimiento", ${ }^{54} \mathrm{de}$ ahí que, "la determinación de las medidas a adoptarse será posterior a la sentencia y se irá definiendo en el marco de audiencias participativas donde participen las autoridades estatales implicadas y los beneficiarios y actores sociales". ${ }^{55}$

Debido a lo anterior, los jueces al revisar el marco jurídico o una parte de ella respecto a las políticas públicas generan una interacción entre órganos públicos, lo cual permite su cooperación y flexibilidad en las decisiones de políticas con mayor información y argumentos posterior a la propia revisión judicial para construir soluciones estables y paliar puntos ciegos en el ámbito legislativo - a) debido a presiones en el proceso legislativo el dictado de leyes que admiten mecanismos no conforme a derecho, b) la falta de perspectiva del impacto de la leyes dictadas en los derechos de los ciudadanos, c) la ausencia de dimensión respecto hasta qué punto las demandas basadas en derechos particulares pueden llegar a acomodarse con un costo tolerablemente bajo en el marco del propio objetivo legislativo ${ }^{56}$ - cargas de inercia - al dejar pasar ciertas demandas basadas en ciertos derechos por atender otras prioridades legislativas,

promotor de la deliberación democrática, Argentina, XXI Siglo veintiuno editores, 2014, p. 213 .

54 Rodríguez Garavito, Cesar, op.cit., p.232.

55 Eto Cruz, Gerardo, "Hacia una tipología especifica de sentencias constitucionales para la tutela de los derechos sociales", Pensamiento Constitucional, Perú, Año XV N 15, 2011 , p.123.

56 Cfr. Dixon, Rosalind, "Para fomentar el dialogo sobre los derechos socioeconómicos. Una nueva mirada acerca de las diferencias entre revisiones judiciales fuertes y débiles", en Gargarella, Roberto (Compilador), Por una justicia dialógica. El Poder Judicial como promotor de la deliberación democrática, Argentina, XXI Siglo Veintiuno Editores, 2014, p.68. 
debido a las coaliciones partidistas para alcanzar cierto resultado legislativo ${ }^{57}$ - así como la ineficacia de las políticas por parte de las demás autoridades, tal como acontece en sentencias emitidas por el guardián constitucional en países como Argentina y Colombia en casos como son riachuelo ${ }^{58}$ y desplazamiento forzado ${ }^{59}$ respectivamente, por mencionar algunos.

Como puede advertirse conforme al Estado Constitucional Democrático existente, a través de las sentencias atípicas intermedias aditivas y sustitutivas es posible que el juzgador agregue o modifique criterios de igualación de mejora en las normas jurídicas y políticas públicas, modulando los efectos de constitucionalidad y convencionalidad, interpretación y aplicación, con las alternativas bilaterales, y ante la actual protección de amparo en forma relativa, la emisión de sentencias dialógicas permitiría en su ejecución resolver el problema de financiamiento a las acciones que estarán obligados implementar las autoridades responsables. De tal manera que la impugnación indirecta del gasto público con motivo de derechos humanos logre la adecuada racionalidad de los recursos económicos del país en cada acción pública encaminada a los fines sociales apremiantes.

Así puede apreciarse, frente al innovador bloque de constitucionalidad se encuentra la institución presupuestaria la cual presenta necesidad de actualización de su juridicidad, para evitar problemas

57 Cfr. Ibidem, pp.68-69.

58 Sentencia Mendoza, Beatriz Silcia y otros c/Estado Nacional y otros s/ daños y perjuicios (daños derivados de la contaminación ambiental del Río Matanza-Riachuelo) emitido por la Corte Suprema de Justicia de la Nación, en fecha 8 de julio de 2008, pp.1-29.

59 Sentencia T-025/04, Abel Antonio Jaramillo, Adela Polanía Montaño, Agripina María Nuñez y otros, contra la Red de Solidaridad Social y otros, emitida por la Sala Tercera de Revisión de la Corte Constitucional de Colombia el 22 de enero de dos mil cuatro, pp.1-160. 
de cumplimiento de la tercera etapa de la tutela judicial efectiva de los derechos fundamentales a través del juicio de amparo. Ello es así, pues la realidad nos muestra que aun cuando se dicte sentencia concesoria de amparo, y el Juez ordene a las autoridades responsables realizar acciones para materializar políticas públicas y proteger los derechos humanos controvertidos, si estas actividades requieren recursos económicos que le son insuficientes total o parcialmente, pese a los nacientes criterios de la SCJN en materia presupuestaria, la ejecución de tal sentencia se prolongara en el tiempo.

En este contexto, entre las múltiples respuestas que las autoridades responsables pueden esgrimir para no cumplir con la sentencia de amparo - "la existencia de déficits públicos; el tratarse de autoridades elegidas por el voto popular; el estimar que el juicio es fraudulento; el incumplimiento de programas prioritarios de gobierno; la generación de graves daños al interés general; el tratarse de sentencias dictadas en juicios provocados por administraciones pasadas"60_ llama nuestra atención la falta de partida presupuestal pues las autoridades se escudan tras el principio de legalidad presupuestaria; "no podrá hacerse pago alguno que no esté comprendido en el Presupuesto o determinado por ley posterior"61 así como a la inembargabilidad de los bienes de la administración pública. ${ }^{62}$

Es claro que la existencia de la ejecución de las sentencias de amparo y del principio de legalidad presupuestaria no se contraponen,

60 Alvarado Esquivel Miguel de Jesús, "Un extraño ataque a las ejecutorias de amparo: la insuficiencia presupuestaria de las autoridades administrativas", en Nava Escudero, Oscar, Ortega Maldonado, Juan Manuel (Coordinadores), Derecho Presupuestario (Temas selectos), México, Porrúa, 2006, p.191.

61 Artículo 126 de la Constitución Política de los Estados Unidos Mexicanos.

62 "Las instituciones, servicios y dependencias de la Administración Pública de la Federación y de las entidades federativas, tendrán dentro del procedimiento judicial, en cualquier forma en que intervengan, la misma situación que otra parte cualquiera; pero nunca podrá dictarse, en su contra, mandamiento de ejecución ni providencia de embargo, y estarán exentos de prestar las garantías que este Código exija de las partes", articulo 4 del Código Federal de Procedimientos Civiles. 
pues ambas buscan el cumplimiento de la CPEUM, las primeras para dar contenido a los derechos humanos y el segundo financiando políticas para satisfacer los primeros, de ambos mandatos constitucionales se desprende obligaciones de pago a cargo de los entes públicos, tal como lo ha indicado la SCJN. ${ }^{63}$

Pese a lo anterior, los entes públicos esgrimen no poder cumplir sentencias de amparo ante el cumplimiento del principio de legalidad presupuestaria, si bien pueden eficientar el recurso que poseen en ocasiones al ser insuficiente, justifican esperar una ampliación presupuestaria acorde a los tiempos de quienes integran al ente legislativo. Esto nos permite apreciar la necesaria participación o involucramiento del ente legislativo en la ejecución de la sentencia de amparo tratándose de políticas públicas cuyo cumplimiento requieren de financiamiento no asignado a las autoridades responsables. Situación que implica un adecuado planteamiento estratégico en la demanda, presentarle alternativas al juez para que al emitir sentencia protectora, innove y permita tal circunstancia.

Si bien la ejecución de la sentencia de amparo, hoy permite la aplicación de medidas de apremio para su cumplimiento; ${ }^{64}$ la imposición de multa, la destitución y la consignación de servidores públicos que representan a las autoridades responsables así como a la autoridad superior de aquellas que incumplen la sentencia ejecutoriada, aunado a la oportunidad de contar con prórroga de tiempo para el cumplimiento del amparo, estas resultan insuficientes, ante la necesidad de que los derechos protegidos lo sean a través de políticas con su respectivo financiamiento, pues aun cuando los entes públicos puedan eficientar

${ }^{63}$ Al respecto puede consultarse Tesis: P./J. 7/2011, Semanario Judicial de la Federación y su Gaceta, Novena Época, Tomo XXXIII, Marzo de 2011, p.6, y la Tesis: P. XX/2002, Semanario Judicial de la Federación y su Gaceta, Tomo XV, Abril de 2002, Novena Época, p. 12.

64 Al respecto puede consultarse los artículos 192-198 de la Ley de Amparo, Reglamentaria de los artículos 103 y 107 de la Constitución Política de los Estados Unidos Mexicanos. 
el dinero asignado previamente y superar falsas concepciones del principio de legalidad presupuestario, la materialización de lo ordenado por usía se prolongaría en el tiempo conforme posibilite la ampliación presupuestaria o posteriores asignaciones anuales.

El derecho comparado permite apreciar que ante la situación actual normativa del juicio de amparo, es posible adoptar modalidades de sentencias atípicas de tipo unilateral, bilateral incluso dialógicas, para ello es necesario el adecuado planteamiento en su demanda para la protección de sus derechos afectados así también de la innovación por los jueces de sus sentencias para lograr mejor efectividad de sus resoluciones.

\section{v. Conclusiones}

Los derechos humanos son una prioridad en México, no solo por estar insertos en la máxima norma jurídica del país sino porque son una obligación que ha adquirido el propio Estado ante la comunidad internacional.

Ante una realidad desigualitaria en el país, con grandes y variados problemas nacionales se requieren acciones del Estado que permitan satisfacer las grandes carencias y necesidades de la sociedad, a través de servicios públicos, diseñando, aprobando y ejecutando políticas públicas con su debido financiamiento, para lograr su efectividad basada en perspectiva de derechos humanos conforme a estándares constitucionales e internacionales.

El descuido en la actualización de la institución presupuestaria, ha traído consigo que pese a la existencia del bloque de constitucionalidad en materia de derechos humanos estos últimos no encuentren su satisfacción ante autoridades competentes, y recurran los justiciables a través del juicio de amparo a encontrar solución a la violación a sus derechos.

Así en la relación entre la garantía de amparo y el financiamiento de políticas públicas, permite el acceso de la judicialización de 
la política, empero, la emisión de sentencia así como la ejecución de aquella al ordenar crear o mejorar políticas, los esfuerzos de la SCJN, se han limitado a la eficiencia del uso de recursos económicos dentro de la esfera primigenia de las autoridades responsables, no así a la causa y modalidades que motiva la inadecuada distribución de la riqueza a través de la aprobación del gasto público y la postergada discusión de la redistribución del PEF por indicación del guardián constitucional.

Lograr superar el rezago normativo al menos en la naturaleza del gasto público y los efectos relativos de la sentencia de amparo, permitiría la debida solución al problema y el anticipo de futuras tutelas judiciales, no obstante ello, en la actualidad el derecho comparado nos permite apreciar la existencia de alternativas susceptibles de adaptación para atender el presente conflicto.

Finalmente, la innovación en la solución de este tipo de controversias dependerá del planteamiento estratégico del justiciable, de las resoluciones progresistas de los jueces así como de la colaboración y cooperación de los demás entes públicos para brindar servicios que hagan efectivos los derechos de las personas.

\section{Vi. Fuentes de información}

\section{BiBLIOGRAFÍA}

Alvarado Esquivel, Miguel de Jesús, "Un extraño ataque a las ejecutorias de amparo: la insuficiencia presupuestaria de las autoridades administrativas", en Nava Escudero, Oscar, Ortega Maldonado, Juan Manuel (Coordinadores), Derecho Presupuestario (Temas selectos), México, Porrúa, 2006.

Álvarez Ledezma, Mario I, "Derechos Humanos y Políticas Públicas" en Rossi, Andrea, Zavala, Luis Eduardo (coords), Políticas Publicas y Derechos Humanos en México, México, ITESM, 2010. 
Astudillo, Gesar, "El bloque y el parámetro de constitucionalidad en la interpretación de la Suprema Corte de Justicia de la Nación", en Carbonell, Miguel, Fix-Fierro, Héctor, González Pérez, Luis Raúl, Valadés Diego (Coordinadores), Estado constitucional, derechos humanos, justicia y vida universitaria. Estudios en homenaje a Jorge Carpizo. Estado Constitucional, México, UNAM-IIJ, 2015, Tomo IV, Volumen 1.

Báez Silva, Carlos, La inconstitucionalidad por omisión legislativa en México, México, Porrúa, 2009.

Becerra Ramírez, Manuel et al., "La soberanía en la era de la globalización”, en Becerra Ramírez, Manuel, Müeller Uhlenbrock, Klaus Theodor, Soberania y juridificación en las relaciones internacionales, México, UNAM-IIJ-Facultad de Estudios Superiores Acatlán, 2010.

Carpizo, Jorge, Carbonell, Miguel, Derecho Constitucional, México, Porrúa, 2010.

Centro De Estudios Legales y Sociales (CELS), Litigio estratégico y derechos humanos. La lucha por el derecho, Argentina, Centro de Estudios Legales y Sociales (CELS)- XXI Siglo veintiuno Editores, 2008.

Chapoy Bonifaz, Dolores Beatriz, Gasto y financiamiento del Estado, México, UNAM-IIJ, 2013.

DíAz Rivorio, Francisco Javier, Interpretación de la constitución y justicia constitucional, México, Porrúa-IMDPG, 2009.

Dixon, Rosalind, "Para fomentar el dialogo sobre los derechos socioeconómicos. Una nueva mirada acerca de las diferencias entre revisiones judiciales fuertes y débiles”, en Gargarella, Roberto (Compilador), Por una justicia dialógica. El Poder Judicial como promotor de la deliberación democrática, Argentina, XXI Siglo Veintiuno Editores, 2014, p.68.

Figueroa Mejía, Giovanni A., Las sentencias constitucionales atípicas en el derecho comparado y en la acción de inconstitucionalidad mexicana, México, Porrúa, 2011.

Fernández Rodríguez, José Julio, "Inconstitucionalidad por omisión", en Carbonell, Miguel, (Coordinador), En busca de las normas ausentes, México, UNAM-IIJ, 2007. 
Fix-Zamudio, Héctor, Ferrer Mac Gregor, Eduardo, Las sentencias de los tribunales constitucionales, Lima, Centro de Estudios Constitucionales-Tribunal Constitucional-Adrus S.R.L., 2009.

Gutiérrez Rivas, Rodrigo, Salazar Ugarte, Pedro, Igualdad, no discriminación y derechos sociales. Una vinculación virtuosa, México, CONAPRED, 2011.

GutiérRez Rivas, Rodrigo, "La categoría de discriminación y su relación con el paradigma de los derechos humanos: un apunte crítico" en Anglés Hernández, Marisol, Burgos Matamoros Mylai, Capdevielle Pauline, Sin Derechos, exclusión y discriminación en el México actual, Colección Líneas de investigación institucionales, México, UNAM, 2014.

OCDE, Getting it Right Prioridades Estratégicas para México, Francia, Éditions OCDE, 2018.

Pardo Rebolledo, Jorge Mario, "El papel de las cortes constitucionales en la justiciabilidad de los derechos económicos, sociales y culturales”, en Cervantes Alcayde, Magdalena, et. al., (coordinadores) ¿Hay justicia para los derechos económicos, sociales y culturales? Debate abierto a propósito de la reforma constitucional en materia de derechos humanos, México, SGJN-UNAM-IIJ, 2014.

Rodríguez Garavito, Cesar, "El activismo dialógico y el impacto de los fallos sobre derechos sociales", en Roberto Gargarella (Compilador), Por una justicia dialógica. El Poder Judicial como promotor de la deliberación democrática, Argentina, XXI Siglo veintiuno editores, 2014.

Uribe Arzate, Enrique, "Mecanismos e instrumentos para la justicia constitucional", en Corzo Sosa, Edgar, I Congreso internacional sobre justicia constitucional, México, UNAM, 2009.

VÁzQuez, Rodolfo, Derechos Humanos Una lectura liberal igualitaria, México, UNAM-IIJ-ITAM-GEAD, 2017.

REFERENCIAS ELECTRÓNICAS

Consejo Nacional de Evaluación de la Política de Desarrollo Social, "Medición de la pobreza", en: <https://www.coneval.org.mx/Medicion/MP/Paginas/Pobreza_2016.aspx>, consultado el día 16 de septiembre de 2018. 
Instituto Nacional de Estadística y Geografía, "Población", en: <http:// www.beta.inegi.org.mx/temas/estructura/>, consultado el día 16 de septiembre de 2018.

ReVISTAS

Blyberg, Ann, "The case of the mislaid allocation: economic and social rights and Budget work", Sur.Magazine international journal on human rights, Brasil, São Paulo, V. 6, N. 11, Dec., 2009, p.150.

VAzQuez, Daniel, De la Place Domitille, "Public Policies from a Human Rights Perspective: A Developing Field", Sur. Magazine international journal on human rights, Brasil, São Paulo, v.8, n.14, jun. 2011, p.40.

Eтo Gruz, Gerardo, "Hacia una tipología especifica de sentencias constitucionales para la tutela de los derechos sociales", Pensamiento Constitucional, Perú, Año XV, N 15, 2011 , p.123.

Sentencias supranacionales e internacionales

Corte IDH, Caso Velásquez Rodríguez vs. Honduras (1998).

Sentencia Mendoza, Beatriz Silcia y otros c/Estado Nacional y otros s/ daños y perjuicios (daños derivados de la contaminación ambiental del Río Matanza-Riachuelo) emitido por la Corte Suprema de Justicia de la Nación de Argentina, el 8 de julio de 2008, pp.1-29.

Sentencia T-025/04, Abel Antonio Jaramillo, Adela Polanía Montaño, Agripina María Nuñez y otros, contra la Red de Solidaridad Social y otros, emitida por la Sala Tercera de Revisión de la Corte Constitucional de Colombia el 22 de enero del 2004.

Tesis y jurisprudencia de la Suprema Corte de Justicia DE LA Nación

Tesis: P./J. 24/99, Semanario Judicial de la Federación y su Gaceta, Novena Época, Tomo IX, Abril de 1999, p.251. 
Tesis: P. CLXVIII/97, Semanario Judicial de la Federación y su Gaceta, Novena Época, Tomo VI, Diciembre de 1997, p. 180.

Tesis: P. LXXX/99, Semanario Judicial de la Federación y su Gaceta, Novena Época, Tomo X, Noviembre de 1999, p. 40.

Tesis: II.2o.P.74 P, Semanario Judicial de la Federación, Novena Época, Tomo XVIII, Julio de 2003, p. 1024.

Tesis: P. XX/2002, Semanario Judicial de la Federación y su Gaceta, Novena Época, Tomo XV, Abril de 2002, p.12.

Tesis: IV.2o.A.56 A, Semanario Judicial de la Federación, Novena Época, Tomo XIX, Enero de 2004, p. 1549.

Tesis: P./J. 11/2006, Semanario Judicial de la Federación y su Gaceta, Novena Época, Tomo XXIII, febrero de 2006, p.1527.

Tesis: P. XIV/2007, Semanario Judicial de la Federación y su Gaceta, Novena Época, Tomo XXV, Mayo de 2007, p.1533.

Tesis: P./J. 134/2008, Semanario Judicial de la Federación y su Gaceta, Novena Época, Tomo XXVIII, Octubre de 2008, p.43.

Tesis: 2a. XII/2009, Semanario Judicial de la Federación y su Gaceta, Novena Época, Tomo XXIX, Marzo de 2009, p. 475.

Tesis: P. LXVII/2011(9a.), Semanario Judicial de la Federación y su Gaceta, Décima Época, Libro III, Diciembre de 201 1, Tomo 1, p.535.

Tesis: P./J. 5/2011, Semanario Judicial de la Federación y su Gaceta, Novena Época, Tomo XXXIII, Marzo de 2011, p. 10.

Tesis: P./J. 7/201 1, Semanario Judicial de la Federación y su Gaceta, Novena Época, Tomo XXXIII, Marzo de 2011, p.6.

Tesis: 1a./J. 18/2012 (10a.), Semanario Judicial de la Federación y su Gaceta, Décima Época, Libro XV, Diciembre de 2012, Tomo 1, p.420.

Tesis: I.3․ (I Región) 19 A (10a.), Gaceta del Semanario Judicial de la Federación, Décima Época, Libro 1, Diciembre de 2013, Tomo II, p. 1207.

Tesis: I.3o.(I Región) 20 A (10a.), Gaceta del Semanario Judicial de la Federación, Décima Época, Libro 1, Diciembre de 2013, Tomo II, p. 1208. 


\section{路}

REVISTA DEL POSGRADO EN DERECHO DE LA UNAM

NUEVA ÉPOCA, NÚM. 1O, ENERO-JUNIO 2019

Tesis: IX.1 o.5 A (10a.), Semanario Judicial de la Federación y su Gaceta, Décima Época, Libro XXIV, Septiembre de 2013, Tomo 3, p. 2620.

Tesis: II.1o.T.6 L (10a.), Semanario Judicial de la Federación y su Gaceta, Décima Época, Libro XVII, Febrero de 2013, Tomo 2, p.1301.

Tesis: 1a. XLIII/2014 (10a.), Gaceta del Semanario Judicial de la Federación, Décima Época, Libro 3, Febrero de 2014, Tomo I, p. 644. 